\title{
Junctional Adhesion Molecule A
}

National Cancer Institute

\section{Source}

National Cancer Institute. Junctional Adhesion Molecule A. NCI Thesaurus. Code C118593.

Junctional adhesion molecule A (299 aa, 33 kDa) is encoded by the human F11R gene.

This protein is involved in the regulation of cell-cell junction formation. 